\title{
Rapsi korvaa rypsin jo lähivuosikymmeninä ilmastonmuutoksen edetessä
}

\author{
Pirjo Peltonen-Sainio, Kaija Hakala, Lauri Jauhiainen ja Kimmo Ruosteenoja \\ MTT (Maa- ja elintarviketalouden tutkimuskeskus, Kasvintuotannon tutkimus ja Palveluyksikkö, \\ 31600 Jokioinen) sekä Ilmatieteenlaitos, PL 503, 00101 Helsinki . Sähköposti: pirjo.peltonen- \\ sainio@mtt.fi, kaija.hakala@mtt.fi, lauri.jauhiainen@mtt.fi, kimmo.ruosteenoja@fmi.fi
}

\section{Tiivistelmä}

Rypsi on Suomessa edelleen tärkein öljykasvilaji. Rypsin rinnalla myös rapsin viljelyalojen kasvattamiselle on ollut suurta kiinnostusta. Viime vuosina rapsin viljelyalat ovatkin kasvaneet merkittävästi. Kun vielä 1990-luvulla rapsin osuus öljykasvialasta oli vain noin yhden prosentin luokkaa, nousi ala kasvukaudella 2007 ensimmäisen kerran yli 10 prosentin ollen historialliset $12 \%$. Rapsin merkitys suhteessa rypsiin saattaa edelleen kasvaa ratkaisevasti ilmaston lämmetessä. Ilmastonmuutos ja kasvukauden piteneminen antavat myös lisäpontta satoisuuden parantamiselle kasvinjalostuksen keinoin.

Laskimme MTT:n pitkäaikaisten, virallisten lajikekoeaineistojen (1976-2006) ja Ilmatieteen laitoksella tuotettujen erityisaineistojen (1971-2000) perusteella todennäköisyyksiä, joiden avulla arvioimme rypsin ja rapsin alueellisia tuotantoriskejä. Tarkastelu käynnistyi nykytilanteen kartoituksella ja jatkui keskittyen vain uusimpiin rypsi- ja rapsilajikkeisiin. Tämän jälkeen otimme tarkastelukohteeksi tulevaisuuden, tavoitteena arvioida niin ilmaston lämpenemisen kuin öljykasvien lajikekehityksen mahdollisia vaikutuksia rypsin ja rapsin tuotantovarmuuksiin ja edelleen sadon arvoihin (käyttäen nykyisiä hinnoitteluperusteita vertailun mahdollistamiseksi).

Rypsin ja rapsin tulevaisuuden tuotantovarmuusarviot tehtiin ristiintaulukoimalla kasvinjalostuksen ja ilmastonmuutoksen skenaariot. Käytimme neljää, MTT:n virallisten lajikekoeaineistojen pohjalta tuotettua tulevaisuuden kasvinjalostusskenaariota: 1) jalostus ei onnistu tuottamaan nykyistä parempia rypsi- ja rapsilajikkeita, 2) jalostus tuottaa yhä parempia lajikkeita, mutta saavutukset puolittuvat aikaisempaan nähden, 3) jalostus tuottaa yhä parempia lajikkeita ja samalla nopeudella kuin aiemmin ja 4) jalostuksen aikaansaannokset kaksinkertaistuvat ilmaston muutoksen myötävaikutuksesta. Vastaavasti käytössämme oli neljä ilmastonmuutoksen skenaariota, jotka oli laskettu 19 ilmastonmallin konsensuksena: 1) B1-päästöskenaario ilman, että kasvukausi pidentyisi, 2) B1-skenaario sekä kasvukauden pidentyminen kahdella viikolla, 3) A2-päästöskenaario ilman kasvukauden pidentymistä ja edelleen 4) A2-skenaario pidentyneellä kasvukaudella.

Tuloksemme paljastivat, että rapsin asema on omiaan vahvistumaan rypsin kustannuksella jo aivan lähivuosikymmeninä. Muutos toteutuu nopeasti, vaikka ilmastonmuutos etenisi oletettua hitaammin ja kasvinjalostus tuottaisi tulosta hitaammin kuin tähän asti. Se, että rapsi valtaa tulevina parina vuosikymmenenä merkittävästi tuotantoalaa rypsiltä, lieneekin ensimmäinen odotettavissa oleva, merkittävä ilmastonmuutoksen mukanaan tuoma sopeutumistoimi peltokasvintuotannossamme. 


\section{Johdanto}

Öljykasvien viljelyalan nostaminen on asetettu kansalliseksi tavoitteeksi. Suomi on hyvin poikkeuksellinen öljykasvien tuotantomaa. Se onkin käytännössä viimeisin lauhkean vyöhykkeen öljykasvien tuottaja, jolla rypsi on edelleen tärkein laji ja rapsin asema varsin vähäinen. Rypsin rinnalla myös rapsin viljelyalojen kasvattamiseen on kuitenkin ollut kiinnostusta. Viime vuosina rapsin viljelyalat ovatkin kasvaneet merkittävästi (Peltonen-Sainio ym. 2007). Kun vielä 1990-luvulla rapsin osuus öljykasvialasta oli vain noin yhden prosentin luokkaa, nousi ala kasvukaudella 2007 ensimmäisen kerran yli 10 prosentin ollen historialliset $12 \%$. Rapsialan kasvu näinkin merkittävästi edelliseen vuoteen verrattuna selittynee ainakin osittain rypsinviljelyä poikkeuksellisen ankarasti koetelleista tuholaisista ja taudeista, joita kartoitettiin valtakunnallisella tasolla osana Toimenpiteet öljykasvituotantomme kilpailukyvyn parantaminen: satotason ja viljelyalan nostaminen (RYPSINOSTE) -hanketta.

Suomen lyhyt kasvukausi on perinteisesti suosinut rypsin viljelyä. Rypsi on rapsia aikaisemmin tuleentuva, ja siksi se on tuottanut oloissamme varmemmin korkealaatuista raaka-ainetta teollisuuden käyttöön. Rapsin perinteinen tuotantovarmuutta heikentänyt ongelma on ollut epätäydelliseen tuleentumiseen liittynyt sadon korkea lehtivihreäpitoisuus. Lisäksi rapsin rypsiä parempi satoisuus ei ole päässyt kunnolla oikeuksiinsa kuin vain kasvukausien ollessa pitkäaikaista keskiarvoa selvästi lämpimämpiä (Peltonen-Sainio ym. 2008a).

Kuluneen vuosituhannen kasvukaudet ovat olleet poikkeuksellisen lämpimiä ja merkittävästi viime vuosikymmenien keskiarvojen yläpuolella (Peltonen-Sainio ym. 2008b). Viljelijät ovat saaneet hyviä kokemuksia rapsin viljelystä, mikä on edelleen rohkaissut heitä siirtymään yhä enemmän rypsistä rapsin tuotantoon. Muutos on korostunut erityisesti suotuisimmilla tuotantoalueilla ja ollut lähinnä kokeiluluontoista pohjoisemmassa. Kasvinjalostus on osaltaan tukenut tapahtunutta muutosta rypsin ja rapsin viljelylaajuuksissa, sillä se on tuottanut aikaisemmista lajikkeista edukseen poikkeavia satoisia, mutta sadon laadultaan aiempaa huomattavasti riskittömämpiä rapsilajikkeita (PeltonenSainio ym. 2008a).

Koska kasvukauden lyhyys ja alhainen lämpösummakertymä ovat keskeisiä tuotantoamme rajoittavia tekijöitä (Hakala ja Peltonen-Sainio 2008), rapsin merkitys suhteessa rypsiin saattaa kasvaa ratkaisevasti ilmaston lämmetessä. Ilmaston lämpeneminen antaa myös lisäpontta satoisuuden parantamiselle kasvinjalostuksen keinoin (katso myös www.mtt.fi/rypsirapsi).

\section{Aineisto ja menetelmät}

Laskimme MTT:n pitkäaikaisten, virallisten lajikekoeaineistojen (1976-2006) ja Ilmatieteen laitoksella tuotettujen erityisaineistojen (1971-2000) perusteella todennäköisyyksiä, joiden avulla arvioimme rypsin ja rapsin alueellisia tuotantoriskejä. Tarkastelu käynnistyi nykytilanteen kartoituksella ja jatkui keskittyen vain uusimpiin rypsi- ja rapsilajikkeisiin. Lisäksi otimme tarkastelukohteeksi tulevaisuuden, tavoitteena arvioida niin ilmaston lämpenemisen kuin öljykasvien lajikekehityksen mahdollisia vaikutuksia rypsin ja rapsin tuotantovarmuuksiin ja edelleen sadon arvoihin. Rypsin ja rapsin vertailu perustui kaikilta osin sadon arvoon, jossa käytettiin vertailun mahdollistamiseksi nykyisiä hinnoitteluperusteita (huomioiden erityisesti sadon määrä sekä öljypitoisuus ja lehtivihreäpitoisuus). Sadon arvo laskettiin aina sen perusteella, millä todennäköisyydellä lämpösummaltaan erilaisia kasvukausia on esiintynyt kymmenen vuoden aikana ennen ja esiintyy tulevaisuudessa ilmaston lämmetessä. Tässä kirjoituksessa keskitymme tulevaisuuden skenaarioihin. Yksityiskohtaiset tutkimusmenetelmät löytyvät alkuperäisjulkaisuista Peltonen-Sainio ym. (2008a) ja (2008b).

Tulevaisuusarvioitamme varten Ilmatieteen laitos laski osana Ilmastonmuutokseen sopeutuminen maa- ja elintarviketaloudessa (ILMASOPU) -hankeyhteistyötä Suomelle lämpötilaskenaariot kausille 2010-2039, 2040-2069 ja 2070-2099, keskiarvovuosina 2025, 2055 ja 2085. Laskelmat tehtiin sekä vahvan kasvihuonekaasupäästöjen hillinnän (B1) että jatkuvien päästöjen (A2) tilanteessa (IPCC 2000). Tulokset ovat 19 eri ilmastomallin konsensus kummassakin päästöskenaariossa.

Rypsin ja rapsin tulevaisuuden tuotantovarmuusarviot tehtiin ristiintaulukoimalla kasvinjalostuksen ja ilmastonmuutoksen skenaariot. Käytimme neljää, MTT:n virallisten lajikekoeaineistojen pohjalta tuotettua tulevaisuuden kasvinjalostusskenaariota: 1) jalostus ei onnistu tuottamaan nykyistä parempia rypsi- ja rapsilajikkeita, 2) jalostus tuottaa yhä parempia lajikkeita, mutta saavutukset puolittuvat aikaisempaan nähden, 3) jalostus tuottaa yhä parempia lajikkeita ja 
samalla nopeudella kuin aiemmin ja 4) jalostuksen aikaansaannokset kaksinkertaistuvat ilmaston muutoksen myötävaikutuksesta. Vastaavasti käytössämme oli neljä ilmastonmuutoksen skenaariota: 1) B1-päästöskenaario ilman, että kasvukausi pidentyy, 2) B1-skenaario sekä kasvukauden pidentyminen kahdella viikolla, 3) A2-päästöskenaario ilman kasvukauden pidentymistä ja edelleen 4) A2-skenaario pidentyneellä kasvukaudella.

\section{Tulokset ja tulosten tarkastelu}

Rapsi on selvästi rypsiä satoisampi öljykasvi, vaikka parempi sadontuottokyky ei aina pääsekään oikeuksiinsa Suomen lyhyessä kasvukaudessa. Niin rypsillä kuin rapsilla siementen lukumäärä neliöllä ratkaisee sadon määrän (Peltonen-Sainio ja Jauhiainen 2008). Rypsillä siemenpainolla on kuitenkin rapsia vähäisempi rooli satoisuuden määräytymisessä. Suuremman siemenkoon tuottaminen vaatii yleensä rapsilta pidempää kasvuaikaa ja altistaa oloissamme laaturiskeille, erityisesti siementen korkealle lehtivihreäpitoisuudelle, joka on suoraan kytköksissä siementen tuleentumisasteeseen.

Tarkasteltaessa lähimenneisyyttä rapsin sadon arvoa heikensi erityisesti alttius korkeille lehtivihreäpitoisuuksille. Itse asiassa rypsin ja rapsin riskit olivat tässä suhteessa hyvin päinvastaiset. Rypsillä ei ollut huomattavaa korkean lehtivihreäpitoisuuden riskiä lyhyessäkään kasvukaudessa, kun taas rapsin lehtivihreäpitoisuudet eivät edes suotuisissa kasvuoloissa olleet aivan rypsin veroisia (Peltonen-Sainio ym. 2008a). Rapsin paremmaksi tunnustettu satoisuus ei myöskään päässyt oikeuksiinsa, jos lämpösummakertymät jäivät alhaisiksi. Menestymiserot kaventuivat kuitenkin merkittävästi, kun vertailussa käytettiin vain aivan uusimpia lajikkeita (Peltonen-Sainio ym. 2008a).

Kasvinjalostus on kuitenkin parantanut merkittävästi rapsin tuotantovarmuutta viimeisten vuosikymmenten aikana (Peltonen-Sainio ja Jauhiainen 2008, Peltonen-Sainio ym. 2008a). Kun nykyiset rapsilajikkeet ovat aineistojemme perusteella ottaneet aimo harppauksen eteenpäin niin sadon määrässä kuin laadussa, on rypsin kehityskulku ollut selvästi maltillisempaa. Olemmekin jo nyt tilanteessa, jossa näiden kahden lajin välinen ero tuotantovarmuudessa ja sadon arvossa on kaventunut varsin rajalliseksi. Rypsi on kuitenkin yhä tänä päivänä koko Suomessa (kaikilla tutkituilla perinteisillä ja mahdollisilla tulevaisuuden uusilla viljelyalueilla) keskimäärin rapsia tuotantovarmempi. Rypsin paremmuus korostuu siirryttäessä pohjoiseen ja Sisä-Suomeen, lyhyemmän kasvukauden oloihin. Rypsi lienee myös tulevaisuudessa uusien viljelyalueiden valtaajalaji, joka kuitenkin ilmaston lämmetessä joutunee vähitellen luovuttamaan asemansa rapsille. Rypsin rooli on nytkin korostunut alueilla, kuten Pohjanmaalla, jonne öljykasvien tuotanto on lähimenneisyydessämme laajentunut (Peltonen-Sainio ym. 2007).

Rapsi on siis lähestynyt tuotantovarmuudeltaan merkittävästi rypsiä. On kuitenkin huomattava, että vertailu on tehty aina TE-keskuksittain, jolloin nojaamme kunkin alueen keskimääräiseen tilanteeseen. Alueiden sisäinen vaihtelu on kuitenkin merkittävää. Erityisen suuria vaihteluita tuotantoedellytyksissä esiintyy niillä alueilla, joissa TE-keskus rajautuu mereen tai alueella on runsaasti järviä. Erityisesti Uudellamaalla, Varsinais-Suomessa, Satakunnassa ja Kaakkois-Suomessa on runsaasti keskimääräistä suotuisampia alueita myös rapsin tuotantoon. Harkitessaan siirtymistä rypsin viljelystä rapsiin nyt ja tulevaisuudessa, viljelijän tuleekin peilata omaa tuotantotilannettaan alueen keskimääräiseen tilanteeseen ja arvioida tältä pohjalta tilakohtaisesti rapsin menestymisen mahdollisuuksia.

Kulunut vuosikymmen on ollut monin paikoin keskimääräistä lämpimämpi. Tarkastelun perusteella lämpeneminen noudattaa yllättävän hyvin ilmastonmuutosskenaarioiden ennusteita tai jopa ylittää ne. Ilmaston muutoksen edetessä kaventuu rypsin etu rapsiin nähden nykyisestään ja ilmeisesti melkoisin harppauksin (Taulukko 1). Tämä näkyy ensivaiheessa rapsin merkityksen kasvuna suotuisimmilla tuotantoalueilla. Mikäli kasvinjalostus tuottaa edelleen tulosta samalla tahdilla ja ilmaston muutos etenee ennusteiden mukaisena, tulee rapsi suotuisimmilla tuotantoalueillamme syrjäyttämään rypsin jo parin tulevan vuosikymmenen aikana. Toisaalta tilanteessa, jossa kasvinjalostuksen aikaansaannokset puolittuisivat nykyisestään, sadan asteen lisäys lämpösummassa riittää siihen, että jo nykyisellä öljykasvien tuotantoalueellamme rapsi on rypsiä parempi sadon arvoltaan. Jos lämpösummaa kertyy kyseisessä jalostusskenaariossa vielä 200 astetta lisää verrattuna jaksoon 1971-2000, voisi rapsin viljely laajentua myös nykyiseltä öljykasvien viljelyalueelta uusille tuotantoalueille. 
Taulukko 1. Kasvinjalostuksen ja ilmaston muutoksen mahdolliset vaikutukset rypsin ja rapsin asemaan tulevaisuutemme öljykasvituotannossa. Vertailussa on käytetty eri tulevaisuusskenaarioita. Tulokset ovat tilanteista, joissa kasvukautemme lämpösummakertymä on kasvanut 100, 200 ja 300 asteella nykyisestä edellyttäen, että kasvukausi pitenee noin kahdella viikolla. Lukuarvo kertoo, kuinka monessa TE-keskuksessa (yhteensä 12) rapsi pärjää rypsiä paremmin: + kertoo rapsin sadonarvon olevan 1-15\% rypsiä parempi, ++ 1630\%, +++ 31-45\% ja ++++ yli 45\%. Miinusmerkit tarkoittavat vastaavasti rapsin sadon arvon jäävän rypsiä heikommaksi. Lähde: Peltonen-Sainio ym. 2008b ja www.mtt.fi/rypsirapsi.

\begin{tabular}{|c|c|c|c|c|c|c|}
\hline \multirow{3}{*}{$\begin{array}{l}\text { Jalostuksen } \\
\text { tulevaisuuden } \\
\text { ennuste }\end{array}$} & \multicolumn{6}{|c|}{ Ilmastonmuutoksen skenaariot* } \\
\hline & \multicolumn{3}{|c|}{$\begin{array}{l}\text { Ilmastonmuutosta hillitään voimakkain } \\
\text { päästörajoituksin (B1) }\end{array}$} & \multicolumn{3}{|c|}{$\begin{array}{l}\text { Ilmastonmuutoksen päästörajoituksia ei } \\
\text { oteta käyttöön (A2) }\end{array}$} \\
\hline & $+100^{\circ} \mathrm{C}$ & $+200^{\circ} \mathrm{C}$ & $+300{ }^{\circ} \mathrm{C}$ & $+100^{\circ} \mathrm{C}$ & $+200^{\circ} \mathrm{C}$ & $+300^{\circ} \mathrm{C}$ \\
\hline $\begin{array}{l}\text { Kehitys } \\
\text { pysähtyy }\end{array}$ & $\begin{array}{l}5+ \\
7-\end{array}$ & $\begin{array}{l}12+ \\
0-\end{array}$ & $\begin{array}{l}12+ \\
0-\end{array}$ & $\begin{array}{l}5+ \\
7-\end{array}$ & $\begin{array}{l}12+ \\
0-\end{array}$ & $\begin{array}{l}12+ \\
0-\end{array}$ \\
\hline $\begin{array}{l}\text { Kehitysnopeus } \\
\text { puolittuu }\end{array}$ & $\begin{array}{l}8+ \\
4-\end{array}$ & $\begin{array}{l}12++ \\
0-\end{array}$ & $\begin{array}{l}12+++ \\
0-\end{array}$ & $\begin{array}{l}8+ \\
4-\end{array}$ & $\begin{array}{l}12++ \\
0-\end{array}$ & $\begin{array}{l}12++ \\
0-\end{array}$ \\
\hline $\begin{array}{l}\text { Kehitys } \\
\text { jatkuu } \\
\text { nykyisellään }\end{array}$ & $\begin{array}{l}12+ \\
0-\end{array}$ & $\begin{array}{l}12+++ \\
0-\end{array}$ & $\begin{array}{l}12+++ \\
0-\end{array}$ & $\begin{array}{l}12+ \\
0-\end{array}$ & $\begin{array}{l}12++ \\
0-\end{array}$ & $\begin{array}{l}12+++ \\
0-\end{array}$ \\
\hline $\begin{array}{l}\text { Kehitysnopeus } \\
\text { tuplaantuu }\end{array}$ & $\begin{array}{l}12++ \\
0-\end{array}$ & $\begin{array}{l}12+++ \\
0-\end{array}$ & $\begin{array}{l}12++++ \\
0-\end{array}$ & $\begin{array}{l}12++ \\
0-\end{array}$ & $\begin{array}{l}12+++ \\
0-\end{array}$ & $\begin{array}{l}12++++ \\
0-\end{array}$ \\
\hline
\end{tabular}

* B1-skenaarion mukaan 100, 200 ja 300 asteen lämpötilan nousu tapahtuu 2015, 2045 ja 2085 ja A2-skenaarion mukaan 2015, 2035 ja 2055. 200 ja 300 asteen lisälämpökertymät tapahtuvat myöhemmin B1- kuin A2skenaariossa, jolloin kasvinjalostus ehtii vaikuttamaan enemmän lajien väliseen tulokseen.

\section{Johtopäätökset}

Rypsi on perinteisesti ollut rapsia tuotantovarmempi öljykasvi Suomen oloissa, mutta ero näiden välillä on jo merkittävästi kaventunut kasvinjalostuksen ansiosta. Arvioimme rypsin ja rapsin tuotantovarmuuseroja laskemalla sadon arvoja eri ilmastonmuutosskenaarioissa [IPCC-skenaariot A2 (ei hillintätoimia, nopea muutos) ja B1 (hillintätoimin hidastettu muutos)] ja neljässä eri jalostusskenaariossa (jalostus etenee kuten viimeisen kymmenen vuoden aikana, puolet hitaammin, kaksinkertaisella nopeudella tai ei lainkaan). Tuloksemme paljastivat, että rapsin asema on omiaan vahvistumaan rypsin kustannuksella jo aivan lähivuosikymmeninä siinäkin tapauksessa, että niin ilmastonmuutos etenisi kuin kasvinjalostus tuottaisi tulosta odotettua hitaammin.

\section{Kirjallisuus}

Hakala, K. \& Peltonen-Sainio, P. 2008. Tuleeko Suomesta vilja-aitta, kun ilmasto muuttuu? Maataloustieteen Päivät 2008. www.smts.fi

IPCC 2000. Emissions Scenarios. Special Report of the Intergovernmental Panel on Climate Change. N. Nakicenovic and R. Swart (Eds.), Cambridge University Press, Cambridge, England, 570 pp.

Peltonen-Sainio, P., Jauhiainen, L. \& Hannukkala, A. 2007. Declining rapeseed yields in Finland: how, why and what next? Journal of Agricultural Science in Cambridge 145: 587-598.

Peltonen-Sainio, P. \& Jauhiainen, L. 2008. Association of growth dynamics, yield components and seed quality in long-term trials covering rapeseed cultivation history at high latitudes. Field Crops Research, in process.

Peltonen-Sainio, P., Jauhiainen, L. \& Venäläinen, A. 2008a. Comparing regional risks in producing turnip rape and oilseed rape I Today in light of recent history. Manuscript submitted.

Peltonen-Sainio, P., Hakala, K., Jauhiainen, L. \& Ruosteenoja, K. 2008b. Comparing regional risks in producing turnip rape and oilseed rape II Future with impacts of climate change and breeding. Manuscript submitted. 